\title{
Перспективная селекция баклажан для юга России
}

\section{Н.В. Гераськина, В.В. Огнев}

Представлены актуальные направления селекции баклажана для условий открытого и защищенного грунта. Выделен перспективный исходный материал для различных направлений использования. Дана характеристика перспективным образцам для использования в селекции. В качестве исходного материала для селекции целесообразно использовать сорта и гибриды $F_{1}$ Эскимо, Халиф, Меч самурая Десерт Голиафа, Умка, Альбион и новый линейный материал Кит 53, л 67, л 83, 85/17, 94/16, Л 107.

Ключевые слова: баклажан, селекция, исходный материал, сорт, гибрид, открытый и защищенный грунт.

C оздание генетически разнообразного исходного материала баклажана и его рациональное использование - это основа селекционной работы. Растущие потребности потребителей и различные направления целевого использования продукции диктуют необходимость расширения сортимента культуры за счет сортообразцов с разнообразными биологическими и морфологическими признаками растений, а также с высокими вкусовыми качествами готового продукта.

Культура баклажана пользуется все большей популярностью в России, однако самые крупные страны-производители баклажана находятся в странах Азии, и там он, благодаря своим высоким вкусовым и лечебным качествам, считается овощем долголетия. Основное достоинство баклажана в том, что он непревзойденный источник многих витаминов. Баклажан содержит вещества, способные понижать уровень холестерина в крови. Благодаря этому он приобретает особое значение в диетическом питании [1]. Включение баклажана в рацион питания пожилых людей особенно полезно, так как широкий набор минеральных веществ, прежде всего калия, нормализует сердечную деятельность и водно-солевой обмен.

Баклажан используется для приготовления большого количества блюд в домашней кулинарии и в качестве сырья для консервной промышленности [2]. В нашей стране плоды баклажана потребляют в пищу только в переработанном виде, но в других странах есть специальные виды баклажанов, которые можно употреблять в свежем виде. Плоды маринуют, сушат, солят целыми или фаршированными с различными овощами, готовят икру и сотэ. Очень полезно использование баклажана в качестве гарнира к жирной и мясной пище. Соленые баклажаны на юге заменяют соленые грибы. Разнообразие способов потребления баклажана, широкое его использование в консервной промышленности и в домашней кулинарии вызывает необходимость создания новых сортов и гибридов, пригодных для различных направлений использования.

Исходя из этого, для каждого направления существуют определенные требования к плодам баклажана. Так, например, для приготовления икры необходимо создавать сорта и гибриды с плотной, белой или слегка зеленоватой мякотью плода, со слабой остротой, придающей пикантность готовому блюду, округлой или грушевидной формой. Цвет плодов принципиального значения не имеет, т.к. они при термической обработке изменяют его. В свою очередь, округлая форма обеспечивает меньшую долю неиспользованной части плода [3]. Для приготовления консервных закусок подходят сорта и гибриды с фиолетовой окраской плодов различного оттенка, с плотной, белой мякотью, длинные, цилиндрической формы, диаметром 3-7 см.

Другое важное направление использования баклажана - кулинария, которая условно подразделяется на промышленную и домашнюю. Выделилось в самостоятельное направление использования плодов для приготовления шашлыков и овощей на гриле.
В настоящее время значительные объемы баклажанов завозятся из других стран, в том числе из Юго-Восточной Азии. Их плоды отличаются от плодов нашей традиционной селекции и обладают другими морфологическими признаками. Они имеют сиреневые и лиловые оттенки плодов, с более рыхлой мякотью, которая при термической обработке лучше пропитывается майонезом и другими соусами [3]. Такие плоды очень быстро бланшируются и готовятся, не придают горечь готовому блюду, очень нежные и совершенно лишены остроты.

Для приготовления гриля, шашлыка и разнообразных закусок из печеных баклажанов требуются специальные сорта этой культуры с альтернативной формой и окраской плодов [3]. Эти образцы должны иметь плоды зеленой и белой окраски, цилиндрической формы, с плотной, белой мякотью, лишены горечи, обладать нежным вкусом, не перекрывать аромат и вкус приправ, а гармонично их дополнять и быстро готовиться. Более высокое содержание сахаров в зеленоплодных баклажанах способствует карамелизации при термической обработке и повышает вкусовые качества блюд на гриле.

Отдельное направление - ceлекция на декоративные признаки. Она направлена на создание сортов и гибридов баклажана, пригодных для выращивания в горшках, на балконах и для декоративного озеленения. К таким соортообразцам предъявляют особые требования. Так, для декоративного озеленения необходимы образцы с компактным штамбовым или полураскидистым кустом, сильнооблиствененные, бесшипые, с цветками, собранными в большие соцветия, и продолжительным периодом цветения. Для балконов и выращивания в горшочках подходят карликовые сорта, с укороченными междоузлиями, бесшипые, со слабым опушением листьев и стеблей, с способностью давать высокий урожай при маленькой площади питания. 
Современный рынок овощей переходит на новые стандарты. Все большим спросом пользуются гетерозисные гибриды, имеющие высокую продуктивность, устойчивость к болезням и вредителям, с отличными вкусовыми качествами, бесшипые, с компактным габитусом и низким опушением листьев и побегов. Изменяются и условия выращивания. С каждым годом все больше фермеров переходят на производство баклажанов в условиях защищенного грунта. Для выращивания баклажанов в весенних пленочных теплицах необходимы специальные сорта и гибриды, сочетающие в себе определенные морфологические признаки растений и пригодные для различных направлений использования. Подобные сорта и гибриды должны быть высокопродуктивными, способными образовывать товарные плоды в сочетании с продолжительным периодом плодоношения, с отличными вкусовыми и питательными качествами плодов, с большим содержанием сахаров, витаминов, микро- и макроэлементов. Важен также компактный габитус растения, укороченные междоузлия, низкая закладка первого разветвления, слабая облиственность в сочетании с более жесткой листовой пластинкой, предотвращающая повреждения вредителями, отсутствие опушенности листьев и стебля, бесшипность. Сорта и гибриды должны обладать устойчивостью к биотическим и абиотическим факторам среды.

В связи с этим, цель наших исследований - создание новых сортов и гибридов пригодных для различного целевого использования.

C 2010 по 2018 годы на базе ССЦ «Ростовский» Агрохолдинга «Поиск» в слободе Красюковской Октябрьского района Ростовской области проводили селекционную работу по созданию новых сортов и гибридов баклажана с разнообразной формой и окраской плодов для различных направлений использования и совершенствованию технологий их выращивания. Кроме этого, созданные сорта и гибриды должны сочетать в себе высокие вкусовые, питательные качества и лечебные свойства, позволяющие положительно влиять на здоровье человека [4].

В наших исследованиях мы руководствовались общепринятыми методиками [5]. Материалом для исследований служили образцы мировой коллекции с альтернативной формой и окраской плодов, современные сорта и гибриды отечествен- ной и зарубежной селекции, а также собственный селекционный материал.

За годы работы в общей сложности авторы изучили более 100 сортов и гибридов ведущих мировых компаний по селекции баклажан, а также более 300 образцов собственной селекции. Был получен и передан в ГСИ ценный материал с разнообразной формой и окраской плодов для различных направлений использования. Ряд образцов уже включен в Государственный реестр селекционных достижений, допущенных к использованию. Наиболее перспективные из них: гибрид $\mathrm{F}_{1}$ Эскимо и сорта Халиф, Меч самурая Десерт Голиафа, Умка и Альбион.

Гибрид $F_{1}$ Эскимо - очень ранний (95 суток), растение достигает в высоту 155 см, имеет слабое опушение стебля и листьев. Ранняя урожай-

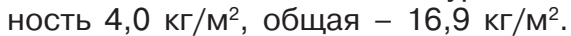
Плоды с яркой глянцевой поверхностью, темно-фиолетовой окраской, округло-овальной формой, сохраняющие товарный вид в течении 12 суток. Мякоть белая, плотная, без пустот, шипы отсутствуют на всем растении, относительно устойчив к фузариозному увяданию. Данный гибрид пригоден для переработки на икру, запекания и приготовления овощей на гриле.

Сорт Халиф - среднеранний (100-120 суток). Куст полураскидистый. Шипы на растении отсутствуют. Плод цилиндрический, длиной 2025 см. Диаметр плода 7 см. Средняя масса плода 200-230 г. Мякоть белая, без горечи. Окраска в технической спелости темно-фиолетовая, поверхность глянцевая. Устойчив к жаре и засухе, относительно устойчивый к фузариозному увяданию. Рекомендуется для переработки и домашней кулинарии. Урожайность $14,5 \mathrm{\kappa г} / \mathrm{M}^{2}$.

Сорт Меч самурая (рис. 1.) среднеранний (100-110 суток). Куст полураскидистый. Шипы на растении отсутствуют. Плод цилиндрический, длиной 20-25 см. Диаметр плода 7 см. Средняя масса плода 230 г. Мякоть белая, без горечи. Окраска в технической спелости темно-фиолетовая, поверхность глянцевая. Рекомендуется для переработки и товарного производства.

Сорт Десерт Голиафа (рис. 2) раннеспелый (100-120 суток) растение высокое (160 см), со средним опушением стебля и листьев. Ранняя урожайность - 4,1кг/м², об- щая - 16,5 кг/M². Плоды с яркой глянцевой поверхностью, темно-фиолетовой окраской, булавовидной формой, сохраняющие товарный вид в течение 12 суток. Мякоть белая, плотная, без пустот, шипы отсутствуют на всем растении, относительно устойчив к фузариозному увяданию. Данный сорт пригоден для приготовления сотэ, шашлыка и закусок.

Сорт Умка (рис. 3) - раннеспелый (100-110 суток) растение достигает в высоту 115 см, имеет среднее опушение стебля и листьев. Ранняя уро-

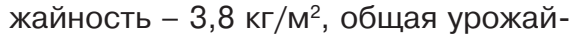
ность - 13,6 кг/м². Плоды с глянцевой поверхностью, белой окраской, цилиндрической формой, сохраняющие товарный вид в течение 8 суток. Мякоть белая, плотная, без пустот, шипы отсутствуют на всем растении или единичные, относительно устойчив к фузариозному увяданию. Данный сорт пригоден для приготовления шашлыка и закусок.

Сорт Альбион - раннеспелый (100-115 суток) растение достигает в высоту 120 см, имеет среднее опушение стебля и листьев. Ранняя урожайность - 4,3 кг/м², общая урожай-

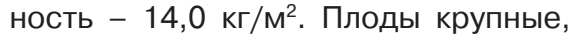
грушевидной формы, с глянцевой поверхностью и белой окраской, сохраняющие товарный вид в течение 8 суток. Мякоть белая, плотная, без пустот, шипы отсутствуют на всем растении или единичные, относительно устойчив к фузариозному увяданию. Сорт пригоден для запекания на гриле.

Готовится к передаче наиболее перспективный образец с зеленой окраской плодов Кит 53 (рис. 4). Этот образец раннеспелый (105115 суток) растение достигает в высоту 130 см, имеет среднее опушение стебля и листьев. Ранняя урожайность - 4,0 кг/м², общая - 13,9 кг/ $\mathrm{M}^{2}$. Плоды с глянцевой поверхностью,

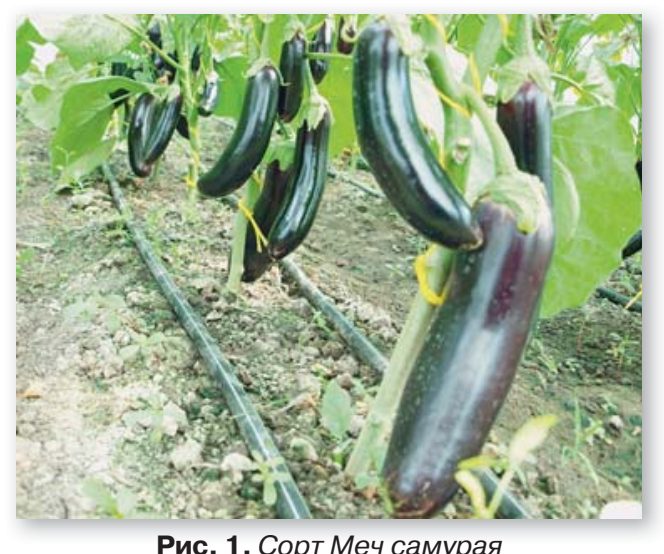

Рис. 1. Сорт Меч самурая 


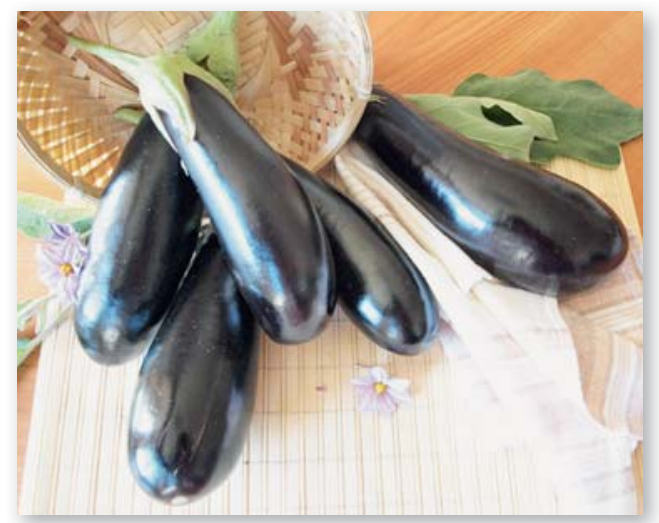

Рис. 2. Сорт Десерт Голиафа

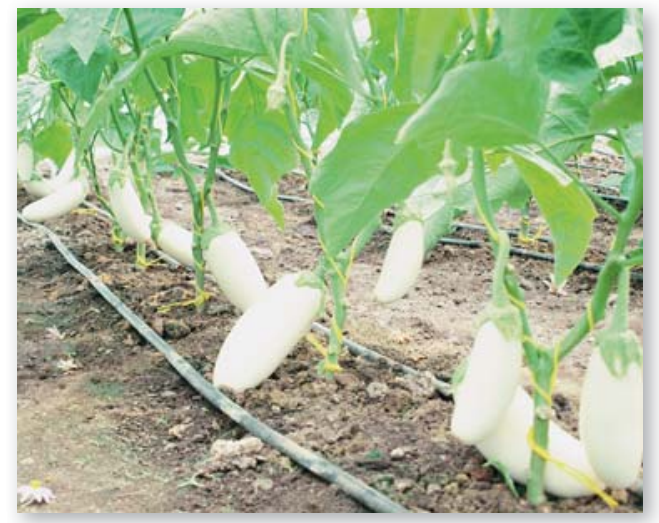

Рис. 3. Сорт Умка

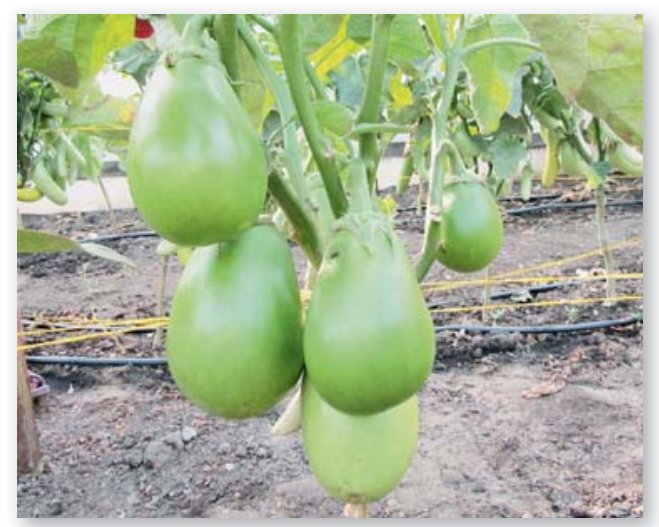

Рис. 4. Перспективный образец Кит 53

грушевидной формы, светло-зеленой окраски. Сохраняют товарный вид в течение девяти дней. Мякоть белая, плотная, без пустот, шипы отсутствуют на всем растении или единичные, относительно устойчив к фузариозному увяданию. Сорт пригоден для запекания и приготовления овощей на гриле.

Также сегодня ведется селекция сортов и гибридов группы «мини-» для горшечного выращивания и декоративного озеленения с различной окраской и формой плодов, ком- пактным габитусом, укороченными междоузлиями, бесшипые, со слабым опушением листьев и стеблей, устойчивые к болезням и вредителям, со способностью давать высокий урожай при ограниченном объеме питательного субстрата.

Скрининг селекционного материала позволил выделить образцы для данного направления с необходимыми параметрами. Наиболее перспективны для декоративного озеленения образцы: Л 67, Л 83, для балконного и горшечного выращивания выделены образцы: 85/17 (рис. 5), 94/16 (рис. 6), Л 107, которые имеют компактный куст, укороченные междоузлия, сильную облиственность, низкую опушенность стеблей и листьев, обладают бесшипостью. Цветки собраны в кисть до 10 шт., масса плода 30-60 г. Плоды пригодны для домашней кулинарии.

Таким образом, на сегодняшний день можно выделить основные направления селекции баклажана:

- селекция на гетерозис;

- селекция на различные направления использования, в том числе для консервной промышленности, кулинарии и декоративных целей;

- селекция на устойчивость к биотическим и абиотическим факторам среды;

- селекция на питательные, ценные и вкусовые качества продукции.

В качестве исходного материала для селекции целесообразно использовать полученные нами гибрид $F_{1}$ Эскимо, сорта Халиф, Меч самурая, Десерт Голиафа, Умка, Альбион и новый линейный материал: Кит 53, Л 67, Л 83, 85/17, 94/16, л 107.

Библиографический список 1.Гиш Р.А. Баклажан. Биология, сорта, технология выращивания. Краснодар, 1999. 168 с

2.Лущиц Т.Е. Перец, баклажаны, физалис. Минск: Книжный Дом, 2001. 80 с.

3.Гераськина Н.В., Огнев В.В. Баклажан для новых направлений использования // Картофель и овощи. 2017. № 7. С. 33-34.

4.Клименко Н.Н., Ховрин А.Н., Огнев В.В. Агрохолдинг «Поиск». Селекция здоровья и долголетия // Картофель и овощи. 2017. № 9. С. 8-11.

5.Литвинов С.С. Методика опытного дела в овощеводстве. М.: ГНУ ВНИИО, РАСХН. 2011. 650 с.

\section{Об авторах}

Гераськина Надежда Викторовна, канд. с.-х. наук, селекционер селекционно-семеноводческого центра «Ростовский», Агрохолдинг «Поиск», с.н.с., Бирючекутская овощная селекционная опытная станция - филиал ФГБНУ ФНЦО.

E-mail: geraskina.89@mail.ru

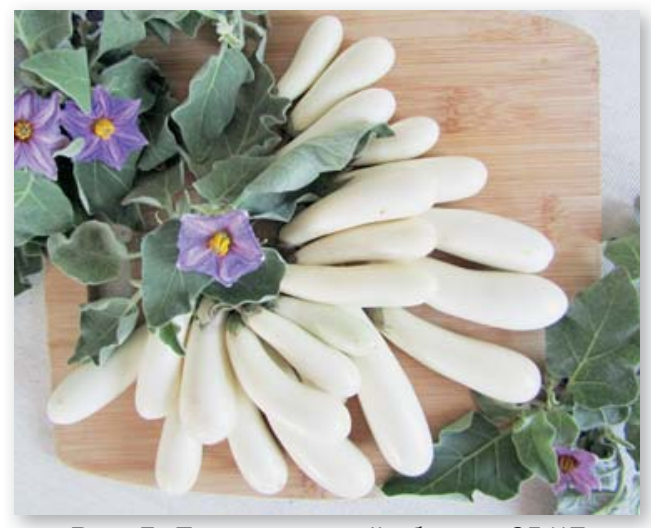

Рис. 5. Перспективный образец 85/17

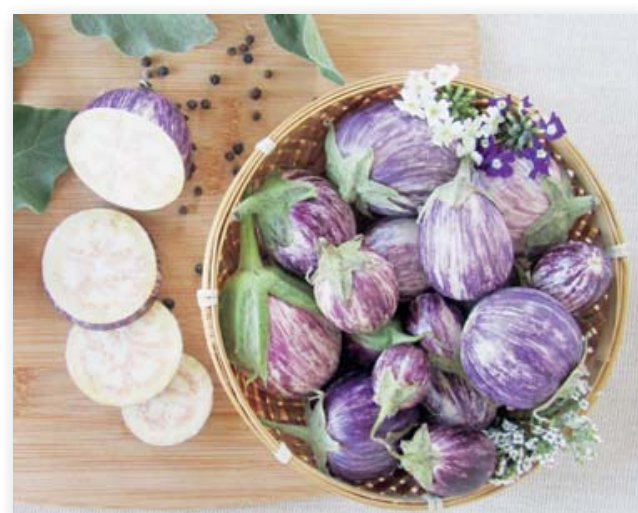

Рис. 6. Перспективный образец 94/16

\section{Огнев Валерий Владимирович,}

канд. с.-х. наук, директор селекционно-семеноводческого центра «Ростовский», Агрохолдинг «Поиск». E-mail: ognevvv@bk.ru

Perspective selection of eggplant for the South of Russia

N.V. Geraskina, PhD, breeder of Plant

Breeding and Seed Center «Rostovskii»,

Poisk Agroholding, senior research fellow of Birutchecutskaya vegetable experimental station - branch of FSBSI FSVC.

E-mail: geraskina.89@mail.ru

V.V. Ognev, PhD, the director of Plant

Breeding and Seed Center «Rostovskii»,

Poisk Agroholding. E-mail: ognevvv@bk.ru

Summary. The perspective directions of selection of eggplant for conditions of open and protected soil are presented. The perspective source material for different directions of use is allocated. The characteristic of perspective samples for use in selection is given. As initial material for breeding it is advisable to use the obtained varieties and $F_{1}$ hybrids Eskimo, Caliph, Sword of the samurai, Goliath Dessert, Umka, Albion, new line material Kit 53, L 67, L 83, 85/17, 94/16, L 107.

Keywords: eggplant, selection, source material, variety, hybrid, open and protected ground. 